\title{
THE EMOTIONAL STATE OF PARENTS IN THE STRUCTURE OF THE STAGES OF THE EXPERIENCE OF HAVING A CHILD WITH DEVELOPMENTAL DISABILITIES
}

\author{
BOGDANNA ANDREYKO \\ Ivan Franko Lviv National University \\ Faculty of Philosophy, Department of Psychology, \\ Doroshenko 41, Lviv 290000, Ukraine \\ E-mail address: aandreykoo@gmail.com
}

\begin{abstract}
The article analyses research data and scholarly approaches to the study: of problems of parents arising from their child's illness; the emotional states of parents raising a child with developmental disabilities; stages of emotional experience related to the birth of a sick child. The family as an integral unit has to face various situations determined by the social impact of the child's disease or impairment, as well as emotional and psychological reactions of the parents to it. Being aware of the psychological stages singled out in the grief theory helps professionals: to understand the reaction of the family of a child with developmental disabilities; realise when and how it is best to intervene, flexibly apply the theory of stages, and account for the specific characteristics of a particular family and individual reactions to such shocks.

Key words: parents, children, disabilities, emotional states, emotional experience and psychological aid

\section{INTRODUCTION}

Traditionally the problem of families who raise children with special needs are considered exclusively through the prism of the child's problems. In most cases, assistance is limited to consulting on the issues of upbringing and education, however little attention is given to a very serious aspect, i.e. the emotional state of the parents themselves. To help them, it is important to understand what happens to a person when his/her child is diagnosed with a disease and how it affects the life on the whole (Mastiukovaya, 2007, p. 35).

The family as an integral unit has to face various situations determined by the social impact of the child's disease or deficiency, as well as emotional and psychological reactions of the parents to it. Families with disabled or
\end{abstract}


chronically ill children face a complex of social problems: cultural, psychological, economic, and educational. Under the contemporary conditions of development of Ukrainian society, a sick child remains a source of stress for the parents and close relatives. Each family, depending on the nature of the child's disease, has its own development situation and is faced with specific problems arising from the need to meet the special needs of the child. Problems such as disorders of relationships with the surrounding people and the violations of the child's rights; communication with the child, hyperprotection, emotional and psychological burden of the parents, however their degree and dynamics depend on the characterological qualities of parents, their type and level of adaptation, as well as the family life cycle. Family life cycles (the author refers to the stages of emotional experience related to the birth of a sick child), especially transitional periods between the stages, induce new social problems for the family: the inability to obtain preventive psychological and educational assistance; lack of information about the disease and pathological condition of the child; and determining the nature of pre-school education. The problems that children experience pertain to their social isolation. The problems singled out as the key ones by parents include medical treatment of the child, finance, correctional training and education (Ivanova, 2000, p.75).

According to researchers, being aware of the psychological stages singled out in the grief theory helps professionals: to understand the reaction of the family of a child with developmental disabilities; realise when and how it is best to intervene, flexibly apply the theory of stages, and account for the specific characteristics of a particular family and individual reactions to such shocks.

The first ones to trace and study the emotional stages experienced by parents when going through the tragedy of birth of a disabled child were such foreign researchers as Elisabeth Kubler-Ross, Jonathan Blasher, Marshall Klaus, Nancy Irvin, John Kennell, Lynn Wikler, etc.

Apart from that, there has been research done into the influence of having a child with disabilities on the adaptation and psycho-emotional state of the parents.

In the theoretical analysis, we will consider and analyse the stages of emotional experience of a sick child birth, as well as the types of emotional response of parents in their child's disease. The practical significance of our research is the basis for designing psychological support for parents raising a child with developmental disabilities.

\section{THE THEORY OF EMOTIONAL STAGES EXPERIENCED BY PARENTS IN RELATION TO THE BIRTH OF A DISABLED CHILD}

Tracing the way parents experience the tragedy of birth of a disabled child, various researchers came to the conclusion that there are regularities in the change of their emotional states on the way towards adaptation. Shock is 
the first reaction when becoming aware of grief. This condition is extremely severe; it may take a long time. However, people instinctively seek stability and begin to doubt: maybe it is not so bad, mistakes happen, we should check everything. This means that a new stage has developed - that of waking up to the problem. Denial-when people believe in healing or incorrectness of diagnosis. It spawns a long and exhausting pilgrimage from doctor to doctor, and then to healers or psychics in the hope to find a miracle that will make the child healthy. Psychologists distinguish the following components in this period: the feelings of guilt, anger, and shame. Loneliness, fatigue from the constant and unsuccessful search for ways to cure the child, the tedious care of the child and the rejection of all own needs and interests results in depression in parents (Severenchuk, 2007, pp.14-15). Depression is the feelings of misery which is decisive in the sequential emotional changes that are unconstructive for they demonstrate the rejection of new reality by parents. Under such circumstances, the conditions for the child's development are extremely unfavourable. Becoming aware of the fact that parental dreams have been lost, throws many into a state of emotional shock (Romanchuk, 2008, p. 18).

For understanding of grief, E. Kubler-Ross $(1969$, p. 3) suggested a model described in her book on death and dying. She identified five stages of grief: "denial, agreement, anger, depression, and acceptance".

J. Blasher (1984) in his review of scholarly works describes 24 studies that supported the stage theory and provided mostly similar stages with some minor discrepancies in their sequence. Below the author provides her own stage model slightly adapted relative to stages of E. Kubler-Ross. It echoes the model M. Irvin, M. Klaus and L. Kennell: shock, denial of the reality or prognosis of disability, waking up to the reality accompanied by feelings of guilt, sadness, despair, anger, etc., gradual reconciliation with and acceptance of the reality, reorganization of life and realistic adaptation to disability (Blasher, 1984, pp. 55-68.).

The experience of practicing psychologists in our country attests to the fact that many families manifest some regular phases on the way towards adaptation (Romanchuk, 2008, p. 14).

Different situations arise from the reaction of parents to the disease, impairment or disability of the child. Michael Semago and R. Mayromyan specify four phases in the reaction of parents to the birth of a child with disabilities. The first one is stress when spouses feel fear, despair and confusion. They ask themselves "Why did this happen to me?". Later, a sense of guilt evolves, despite the doctor saying that the disease was inevitable. The second is the phase of dynamics of the psychological condition of the family, i.e. negativity, denial of the diagnosis. In this case, denial of the pathological condition of the child by parents is viewed as a means (although not perceived as such by them) to overcome depression and anxiety. Some parents express their distrust of doctors and consultants and repeatedly clarify the diagnosis. A characteristic feature of this phase is a projection of their own feeling of guilt upon others, which is of both internal and external nature in relation 
to the family. Parents may blame each other or doctors. The nature of such projections may divert energy from adequately solving the problem, results in tension and increases the emotional tension. In this case, parents are concentrated on the disease, the impairment of the child and do not see any positive traits of her/his personality or preserved capabilities and qualities that are not affected by the disease. The third phase is depression; it is associated with waking up to the reality, loss of hopes that their child may be normal. Sadness and grief often can manifest themselves indirectly, but the fact of experiencing such feelings affects family relationships. Interest in work and other things is reduced; there is irritation, anger, and lack of warmth in the relationship. The continuous need in special care of the child may complicate the tackling of this problem, and intensify the syndrome of "chronic sadness" stemming from the fact that the child constantly depends on his/her parents, as well as a socialization of his/her mental or physical impairment. This can lead to emotional isolation and alienation spouses. Some couples stay together due to the common sense of guilt and duty, but their satisfaction in the marriage can diminish, sexual disharmony can occur. The fourth phase marks the beginning of social and psychological adaptation of family members and adequate emotional contacts. According to M. Semago and R. Mayromyan, these stages are structural in their nature rather than sequential and time-related; and depending on the microenvironment and specific features of the internal family situation, they may have a different duration and manifestations (Semago, 1991, p.72).

Despite the fact that much of the research confirmed the existence of the stage process, there are new studies (Wikler, 1981, p.188) that claim that in fact these realities can recur, overlap and occur simultaneously, and do not always follow a clear regular sequence. This vision is articulated into the theory of inconsistent stages by Milton Seligman and Rosalyn Darling (1989): "The Stages must be viewed flexibly, taking into account the complexity of families and unpredictability of the consequences of the event in each individual case. Although the reactions described proponents of the theory of stages can be traced to parents of children with special needs, these reactions do not have to be consecutive They can actually recur cyclically; they can be spawned again by various life crises and turning points".

In our opinion, all classifications of the stages of experiencing and emotional reactions of parents to the birth of a child with disabilities are very informative and provide psychologists with indispensable information. Clearly, all classifications and stages are results of long term practical and research work, and by no means should we discount the results of their work. However, we should also remember that all people are different, they cannot be fitted into one framework, and therefore not all parents can and should go through the stages of emotional experience in relation to the birth of a sick child at the same time, in the same way or even in the same sequence. Research calls for impartiality, regularity and sequence should be considered as individually as possible for each person. Many scholars base their stages 
research on emotional states. For example, E. Kubler-Ross, J. Blasher, M. Irvin, M. Klaus and L. Kennell came to the conclusion that there are regularities in the change of their emotional states on the way towards adaptation. According to M. Semago and R. Mayromyan, these stages are structural in their nature rather than sequential and time-related; in his classification, he identifies 4 phases of reaction of parents on the birth of a child with disabilities, each of which is accompanied by a related emotional state. The study turned out to be very informative for our research, thus we identified the main criteria for exploring the emotional state of parents in practical research, namely: anxiety, depression, the feeling of guilt, frustration, shock, aggression, anger, in our opinion self-esteem of the emotional state, well-being, activity, and mood .Our goal is to structure and determine the level of emotional stress in groups, because in our view the emotional state of parents depends on the condition, severity and the course of the child's disease.

Besides, another objective of our practical research implies the search for new emotional states of parents that have not been explored yet. By applying practical psychology methods such as conversation, content analysis, as well as formative and ascertaining experiments, we intend to achieve the above listed objectives and set tasks.

\section{PARENTAL BEHAVIOUR DISORDER}

It is necessary to consider the available research evidence about parental behaviour disorders in case of birth of a sick child. Typical disorders of parental behaviour in case of birth of a sick child include:

Hyper protection. The "fear to lose the child" style or concealed or obvious alienation is related to the mental deprivation of the child. Hyper protection may stem from disbelief in the child's abilities and capacities, as well as with the "fear to lose the child". The hypertrophied fear for the child is transmitted from mother to the child inducing "dependent" behaviour. In such cases, independence of the child is not even an issue.

Emotional rejection. It most often occurs when the child does not justify the expectations of parents or does not satisfy their social ambitions, which is manifested in an increased level of anxiety in the child's educational neglect and deviant behaviour in older age. The lack of responsiveness of parents is expressed as untimely and inadequate response to the needs of children and neglecting their feelings. They may exhibit excessively intense reactions to deviations in the child's behaviour and ignore positive phenomena. Insensitivity of parents, especially mothers, results in a situation of deprivation, further slows down the development of the child, and induces disorders in his/her behaviour. Affection to mother is a necessary stage of mental development. With the mother's support, the child acquires confidence, becoming active in cognizing the world. For a child who falls behind in mental development, the relevance of such support is obvious. In our opinion, disorders 
in parental behaviour emerge in case if omission of the stages of adaptation to the birth of a child with development disorders. This behaviour should be researched more in detail, because it results in the pedagogical neglect, cessation of the child's mental development and changes to her/his personal sphere.

It is important to emphasize that the age of the infant is divided into three stages: newborn (first 4-6 weeks), first half a year (the leading activity at this stage is situational and personal communication with adults, the emergence of "the invigoration complex recovery"), the second half year of the child's life (the leading activity at this stage is object-manipulative). It is well-known that a number of diseases (some neuro infections, children's infectious diseases) can cease the mental development of children. However, mental retardation may develop not only due to the disease itself and the associated brain damage, but because of the influence of the environment of the child. The best known reasons of mental retardation include the cases of so-called educational neglect and hospitalism. Especially adverse effects stem from the deficit of communication with adults in the first year of life, i.e. in infancy (Ivanova, 2000, p.192). As we see, during the first year of life for a healthy baby it is very important to communicate with parents. In our view, for a child born with certain disorders of communication and establishment of emotional contact with parents is an indispensable component of their future development; and for their family it is harmony in the relationship.

In work Social psychological problems of disabled children (Ivanova, 2000, pp. 62-65) highlights the problem of parents raising children with congenital or acquired mental and physical development impairments and chronic diseases. Following practical and scholarly research, the author shows that parents' rate financial and material problems as the most important; next are psychological problems, nervous overload, misunderstanding, abandonment, loneliness, and moral issues; while treatment and rehabilitation of the child come third.

Michael Roberts (1997, pp. 308-310) notes that the main factors that determine the probability of positive adaptation of the child to his/her disability include characteristics of her/his family: the personality of parents, the quality of the marital relationship and characteristics of relationship between the parents and the child, to what extent the parents managed to accept the child's disability and learn to live with it: "Parents who effectively overcome difficulties accordingly can satisfy emotional needs of the child and other family members, provide adequate medical care and cope with the demands at work and at home". "A disabled child develops best when parents can provide an atmosphere of acceptance and love in the family. However, with regard to "acceptation" it is important not cross a certain limit, because despite the unconditional acceptance of the parents it is also important to ensure a certain discipline, specific requirements and expectations concerning the child, to teach him/her proper behaviour among other children, to develop his/her independence. In a healthy environment, there should be a 
balance between recognition and acceptance of the child's constraints, on the one hand, and supporting the development of his/her abilities and required skills, on the other hand (Roberts, 1997, p. 310).

To quote the famous words by Bruno Bettelheim (Romanchuk, 2008, p. 334): "Children can learn to live with their disabilities, but they can never be happy if they do not feel that they are loved and invaluable for their parents. If parents accepting the child's disability love him/her the way he/she is, then the child can believe that in the future he/she will love and be loved. With this faith, the child can happily live day to day without fear, but looking to the future with hope...".

\section{CONCLUSION}

For practical work with parents, we have concluded that the child's health is the key point, but paradoxically as it seems parents see the issue of finances and emotional state as the most important ones. Obviously, in order to help the child cope with the disease, in order to solve all the problems associated with raising a child, parents need a healthy or at least optimally healthy psychological state. Normal emotional state of parents and good psychological climate in the family can empower parents and open new resources they might have no idea about. We believe that the emotional states of parents are determined by the child's disease and problems arising from the disease during the upbringing of the child with disabilities. In our opinion, all classifications of the emotional stages and reactions of fathers to the birth of a child with disabilities are very informative and useful for psychologists. Clearly, all classifications and stages are results of long term practical and research work, and by no means should we discount the results of their work. However, we should also remember that all people are different, they cannot be fitted into one framework, and therefore not all parents can and should go through the stages of emotional experience in relation to the birth of a sick child at the same time, in the same way or even in the same sequence. Research calls for impartiality, regularity and sequences should be considered as individually as possible for each person.

\section{REFERENCES}

[1] Blasher J. (1984). Sequential stages of parental adjustment to the birth of a child with handicaps: factor artefact? Mental retardation, 22. 55-68.

[2] Hluhaniuk T. [n.d.]. The psychologist's aid for families raising a child with intellectual disabilities. Retrieved (26.02.2016) from:http://www.ippo.if.ua/predmety/ocppsr/index.php?r=site/ stattya\&id $=76$.

[3] Ivanova I. B. (2000). Social and psychological problems of children with disabilities. Logos, 87.

[4] Kubler-Ross E. (1969). On death and dying. New York: Macmillan.

[5] Mastiukovaya E. M. (2007). Therapeutic pedagogy (early and pre-school age). VLADOS, 258

[6] McDonald E. (1971). Understand those feelings. Pittsburg: Stanwix House Inc.

[7] Nakazna I. M. (2012). Fundamentals of clinical psychology and pathopsychology: manual. Nizhyn: 
Gogol NSU.

[8] Ostrovs'ka K. O. (2013). Psychological bases of formation of social competence of children with autistic disorders. Ostrovskaya: Kyiv.

[9] Roberts M. (1997). Handbook of Pediatric Psychology. New York: Guilford Press.

[10] Romanchuk O. A. (2008). Disabled child in the family and society. Lviv: Litopys.

[11] Severenchuk H. (2007). Psychological correction work with mothers of children from special needs. Pathologists, 3, 14-15.

[12] Semago M. M. (1991). Key aspects of the psychological approach when consulting families with children with developmental disorders. Collection of scholarly works, 130.

[13] Seligman M., Darling R. (1989). Ordinary families, special children: a systems approach to childhood disability. New York: The Guilford Press.

[14] Wikler L. (1981). Chronic stresses off a milies of mentally retarded children. Family Relations, 30, 281-188. 